Iraqi Journal of Information and Communications Technology(IJICT)

Conference Series: The $1^{\text {st }}$ Conference of Applied Researches in Information Engineering(ARIE2021), 2021

ISSN:2222-758X e-ISSN:2789-7362

\title{
RECONFIGURABLE MONOPOLE ANTENNA DESIGN BASED ON FRACTAL STRUCTURE FOR 5G APPLICATIONS
}

\author{
Amna S. Kamel ${ }^{1}$, Ali S. Abdulhadi ${ }^{2}$ \\ 1,2 College of Information Engineering, Al-Nahrain University, Baghdad, Iraq \\ amna.shibib@ieee.org ${ }^{1}$, ali.sadeq@coie-nahrain.edu.iq ${ }^{2}$ \\ Received:24/4/2021, Accepted:1/6/2021
}

\begin{abstract}
In this paper, a reconfigurable antenna design for 5G applications is presented. It is based on monopole antenna and fractal structure. The antenna is designed and simulated by using CST Microwave studio. The design structure consists of (monopole) feedline, ground plane, L-shape reflector, fractal structure and PIN diodes. The antenna is printed on $(25 \times 29 \times 1.6 \mathrm{~mm}) \mathrm{FR}-4$ substrate of $\varepsilon_{r}=4.3$ and $\tan \delta=0.001$. The antenna shows a resonant frequency at 4.1 GHz with $S 11=-11.4 \mathrm{~dB}$ and an Omni-direction pattern of $1.21 \mathrm{~dB}$ gain. The L-shaped reflector is used to maintain the radiation pattern in a specific direction. Moreover, the proposed fractal structure is found to operate as a matching circuit to give another resonant frequency and enhance the antenna performance. Where it is used to give more manipulation in the antenna performance including frequency resonance and radiation patterns. The PIN-diodes are used to give many cases for more current manipulation. Moreover, the authors used RF (50 $\Omega$ SMA port) between the monopole antenna and the right side of the ground plane to optimize directing radiation pattern and to eliminate the problems of interference between $\mathrm{AC}$ and $\mathrm{DC}$ that were produced from using PIN diode. This manipulation leads to change the resonant frequency and radiation pattern to the desired direction. So, all three parts are printed on a single side of the FR4 substrate with no metallization coating on the opposite side. Finally, the HFSS environment is invoked too for more results validation.
\end{abstract}

keywords: Monopole antenna, Reconfigurable antenna, Fifth generation mobile communication network (5G), Fractal.

\section{INTRODUCTION}

In wireless communication systems, many applications operate at frequencies below $6 \mathrm{GHz}$ to ensure high speed guided transmission [1]. For this reason, choosing the low frequencies antenna has declined in recent times [1]. The antenna is one of the most essential components of wireless communications systems because it is used in both transmitter and receiver sides [2]. Dipoles/monopoles, slot/horn antennas, loop antennas, microstrip antennas, reflector antennas, helical antennas, dielectric/lens antennas, log-periodic antennas, and frequency-independent antennas are different types of antennas that have emerged in the last fifty years for both radar and communication systems, each of which is better suited to a specific application than the others [3]. Because of their low cost, lightweight, and ease of fabrication [4], printed antennas are the most suitable ones commonly used in reconfigurable designs [5]. Meanwhile, some techniques are used for gain enhancement and miniaturization [6], [7]. Reconfigurable tools based upon electronic devices for realizing direct handling in one actual structure turns into one of the most critical requirements within the present-day techniques [8]. However, polarization reconfigurable antennas with the benefits of improving system capacity, minimizing fading decrease, and also reducing the channel obstruction has brought a lot of focus amongst the antennas scientists [9]. The various advantages of reconfigurable antennas, however, come with a couple of drawbacks, such as the need for additional antenna modification, which necessitates a more complex regulation. Full usage can necessitate sophisticated signal processing and feedback circuits, and more components and more complex manufacturing processes would almost certainly be required than in traditional antenna system embodiments [10]. For example, the authors in [11] used a biasing network to control their 
antenna performance-based 7 PIN diodes that limit their use in many portable and handheld devices. However, the proposed design in [12], realized a more attractive design by connecting photo resists that do not need for the biasing system; but such devices show a very slow response due to their rising time slop. In [13], the authors used two PIN diodes to obtain a direct antenna modulation by changing the phase array motion; however, the effects of biasing circuit realize a frequency operation sweep due to the wiring system. The antenna proposed in [14] was applied to control the radiation pattern direction from the broadside to an end fire for OFDM systems. Another design was proposed based on beamforming to reduce the interference in the broadcast surrounding [15]. Moreover, fractal based antenna was proposed to improve the efficiency of a partial ground plane antenna when two diodes were connected to the fractal structure [16]. therefore, the authors in [17] proposed design of Double H-Slot Microstrip patch that operate on three frequencies to enhancement gain and to change radiation pattern in many directional. In this paper, the authors give a systematic study of a reconfigurable printed antenna design based on fractal structure for $5 \mathrm{G}$ applications. The CST Microwave studio is used to design and analyze the antenna. So the monopole antenna is designed as a printed strip line over a dielectric substrate with a partial ground plane on the right side only as shown in section II. Next, the L-shaped reflector is added to the monopole antenna to change the radiation direction. Therefore, in section III, the fractal structure is used with the proposed antenna design as a matching circuit to enhance the antenna performance by changing the radiation pattern direction. Later on, the antenna design is connected with four PIN diodes that are located between the reflector and the fractal structures to get reconfigurable frequency and radiation pattern. The RF switches are used to optimize radiation pattern symmetry toward a certain direction which is discussed in section IV. Finally, the HFSS software package is invoked too for more result accuracy.

\section{Antenna Design based L-Shaped Reflector}

In this section, the authors proposed a monopole antenna design that is consisted of a feedline which is printed on FR-4 substrate of $\varepsilon r=4.3$ and $\tan \delta=0.001$. The substrate width is $(\mathrm{W})$ of $29 \mathrm{~mm}$, length $(\mathrm{L})=25 \mathrm{~mm}$, and thickness $(\mathrm{h})=$ $1.6 \mathrm{~mm}$ as shown in Fig. 1. A single ground plane with dimensions of $\left(4 \times 4.5 \mathrm{~mm}^{2}\right)$ is printed on the right side of the feedline. The other geometrical details are presented in Table I.

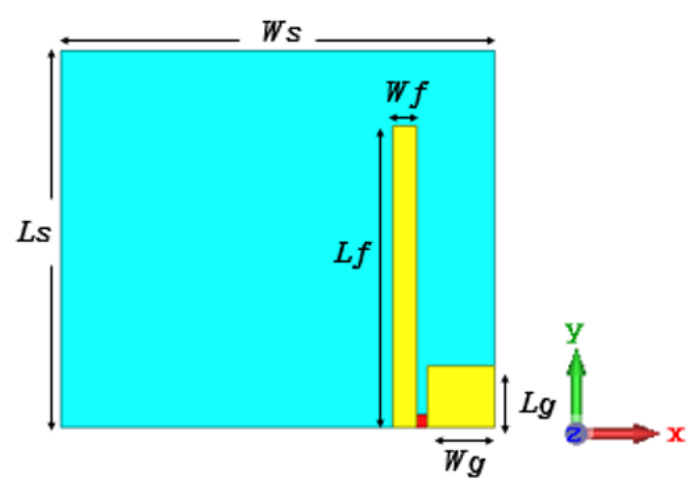

Figure 1: Monopole antenna geometrical design 


TABLE I
Monopole Antenna Geometrical Details
\begin{tabular}{|c|c|c|c|c|c|}
\hline Ws & Ls & Lf & Wf & Lg & Wg \\
\hline $29 \mathrm{~mm}$ & $25 \mathrm{~mm}$ & $20 \mathrm{~mm}$ & $1.5 \mathrm{~mm}$ & $4 \mathrm{~mm}$ & $4.5 \mathrm{~mm}$ \\
\hline
\end{tabular}

The proposed antenna performance is analyzed and $S_{11}$ is shown in Fig. 2. The simulated results show one resonant frequency at $4.1 \mathrm{GHz}$ with an $S_{11}$ value equal to $-11.4 \mathrm{~dB}$ in the CST environment, while it showed $-14.6 \mathrm{~dB}$ at 4.3 $\mathrm{GHz}$ in the HFSS environment. The reason for the difference between them, is that HFSS is based on the Finite Element Method (FEM), while CST is based on the Finite Integration in Technique (FIT). Moreover, the 3D radiation pattern of the monopole antenna at the frequency of $3.76 \mathrm{GHz}$ is presented in Fig. 3. The obtained result shows an Omni-directional radiation pattern with a maximum gain of $1.6 \mathrm{~dB}$.

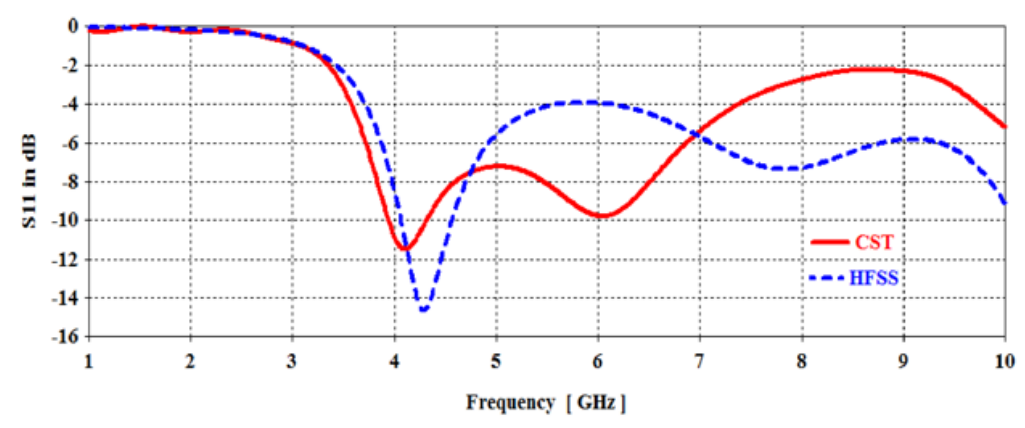

Figure 2: $S_{11}$ in $(\mathrm{dB})$ of the monopole antenna

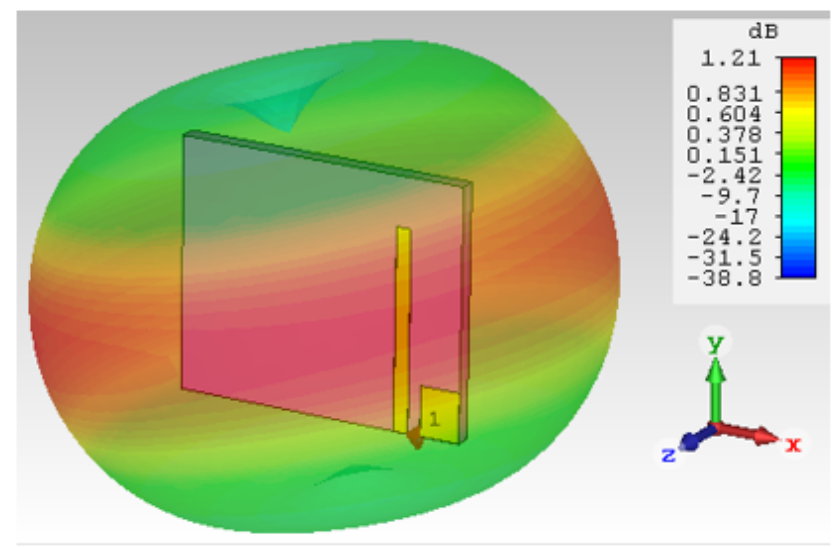

Figure 3: 3D radiation pattern antenna

To maintain the radiation pattern in a specific direction, an L-shaped reflector is added to the left side of the feedline as shown in Fig. 4. The antenna geometrical details are presented in Table II. 


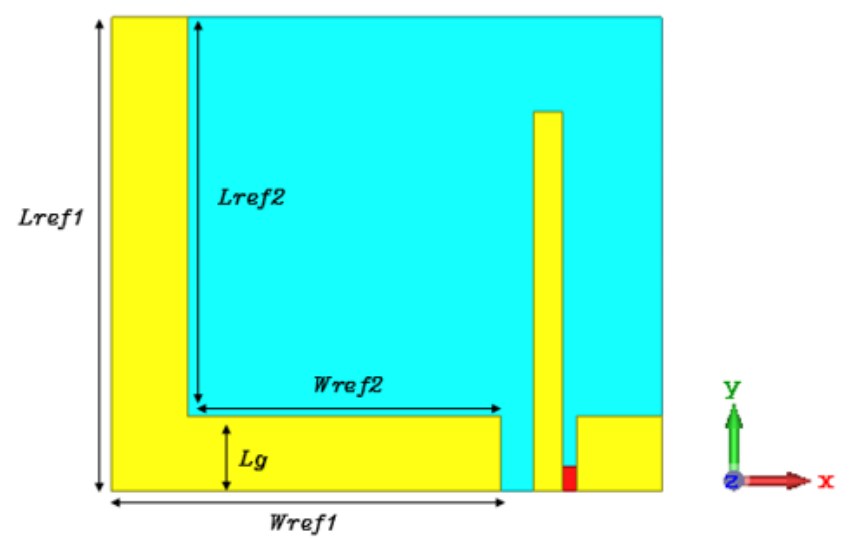

Figure 4: Monopole antenna design with L-shaped reflector

TABLE II
Geometrical Details of Monopole Antenna Design with L-Shape Reflector
\begin{tabular}{|c|c|c|c|c|}
\hline Wref1 & Lref1 & Lref 2 & Wref 2 & Lg \\
\hline $20.5 \mathrm{~mm}$ & $25 \mathrm{~mm}$ & $21 \mathrm{~mm}$ & $16.5 \mathrm{~mm}$ & $4 \mathrm{~mm}$ \\
\hline
\end{tabular}

The antenna performance is analyzed by using CST MWS in terms of $S_{11}$ and radiation patterns. In Fig. 5(a), the $S_{11}$ result is presented to show good enhancement in comparison to the previous design, where the results showed that the antenna gives $S_{11}$ at $4.2 \mathrm{GHz}$ with a value equal to $-27.1 \mathrm{~dB}$. Moreover, the HFSS software package is invoked for more result validation. It is found good agreement is achieved between the two software packages. The 3D radiation pattern antenna is presented in Fig. 5(b). The antenna gain is found equal to $2.6 \mathrm{~dB}$ with a change in the direction of the propagation and as shown in Fig. 5(b).

\section{iII. Reconfigurable Antenna Design based on Fractal}

Reconfigurable antenna design based on Minkowski fractal shaped with slot dimensions calculated as in [18] is presented in Fig. 6. The fractal structure is added to the antenna, located between the feedline and L-Shape Reflector. The fractal structure is characterized by dimensions of $\left(15 \times 15 \mathrm{~mm}^{2}\right)$ with four rectangular slots, each slot is characterized by dimensions of $\left(4.5 \times 5 \mathrm{~mm}^{2}\right)$ located on a different side compared with the other slots. Other geometrical details are presented in Table III. The fractal operates as a matching circuit inside the antenna which provides another resonant and enhances the antenna performance. Moreover, it is used to give more manipulation in the antenna performance, frequency and radiation.

TABLE III

Geometrical Details of Reconfigurable Antenna Based on MTM Structure

\begin{tabular}{|c|c|c|c|c|}
\hline $\mathrm{Lm}$ & Wm & W1 & W2 & W3 \\
\hline $15 \mathrm{~mm}$ & $15 \mathrm{~mm}$ & $5 \mathrm{~mm}$ & $5 \mathrm{~mm}$ & $5 \mathrm{~mm}$ \\
\hline
\end{tabular}


(a)

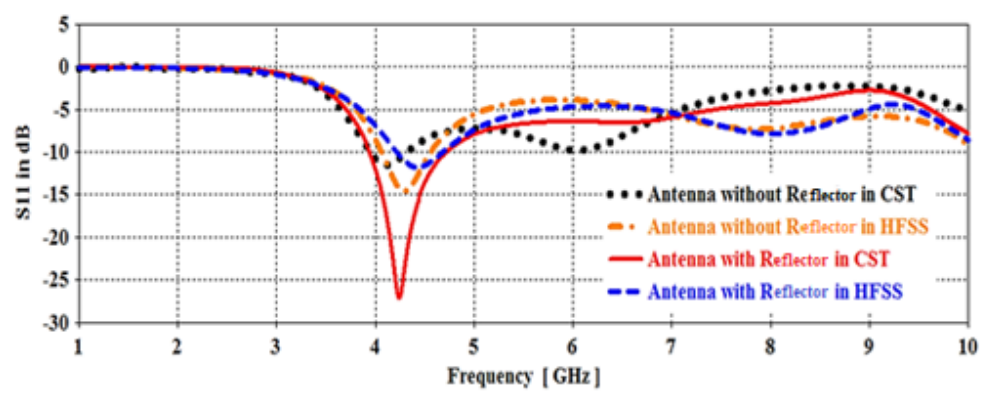

(b)

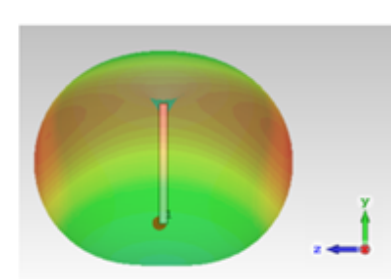

Right Side View

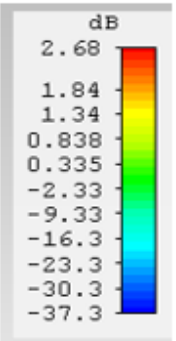

$-37.3$

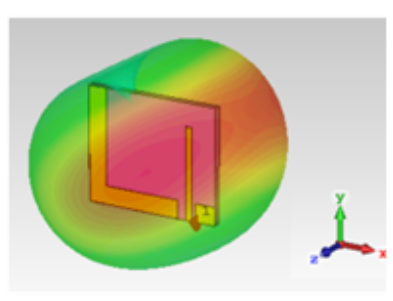

3D View

Figure 5: Antenna performance with and without L-shape reflector: (a) $S_{11}$ spectra and (b) 3D radiation patterns
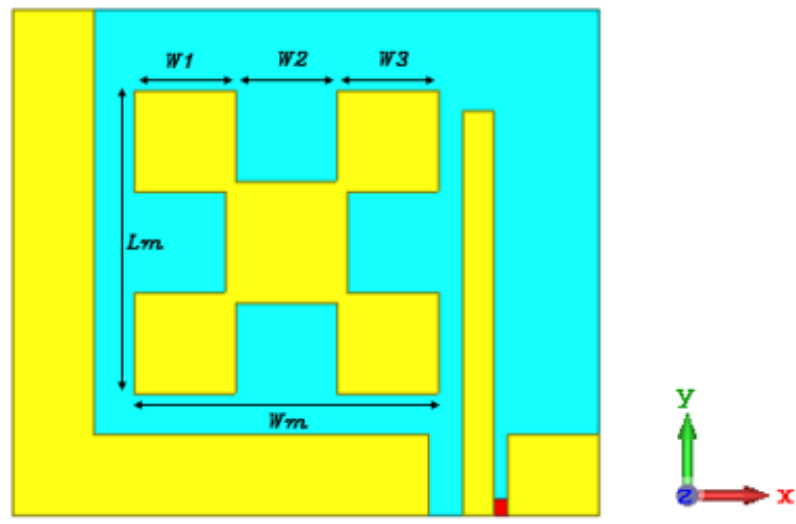

Figure 6: Antenna design based on MTM structure

The antenna is simulated by using a CST environment. The obtained result in terms of $S_{11}$ is presented in Fig. 7(a). It is found that the antenna has two frequency bands. The first one has a resonant at $3.76 \mathrm{GHz}$ with an $\mathrm{S} 11$ value equal to $-30.45 \mathrm{~dB}$, the second resonance is found to be from $4.76 \mathrm{GHz}$ to $6.94 \mathrm{GHz}$ with $S_{11}$ equal to $-19.3 \mathrm{~dB}$ as the best value at a frequency of $5 \mathrm{GHz}$. These results are validated using CST microwave studio in terms of $S_{11}$ spectra. While The obtained result in HFSS is two frequency bands that operate in $3.7 \mathrm{GHz}$ and $9.87 \mathrm{GHz}$ with $S_{11}$ that equal $-13.34 \mathrm{~dB}$ 
and $-58.6 \mathrm{~dB}$ respectively. And the difference is due to the same reasons mentioned previously that each simulator uses a different approach. So The 3D radiation patterns of the proposed antenna are presented in Fig. 7(b). The antenna gain is found to be $1.28 \mathrm{~dB}$ at $3.76 \mathrm{GHz}$, while the antenna gain becomes $2.67 \mathrm{~dB}$ at $5 \mathrm{GHz}$. The antenna shows a broadside radiation pattern at first resonant while the radiation pattern becomes near to endfire $5 \mathrm{GHz}$.

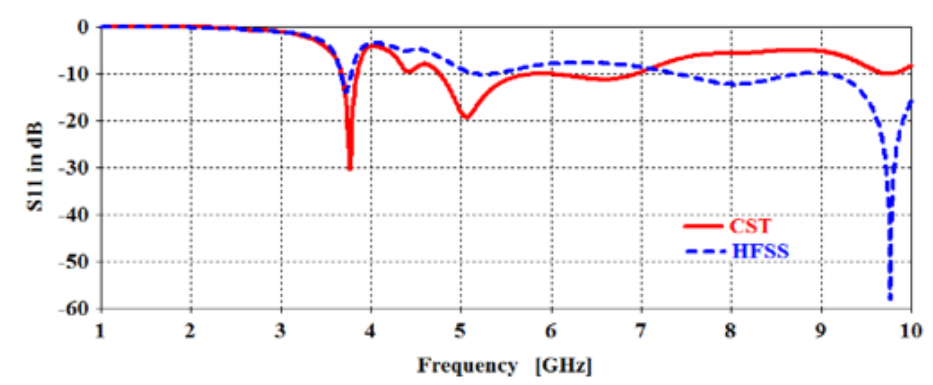

(a)

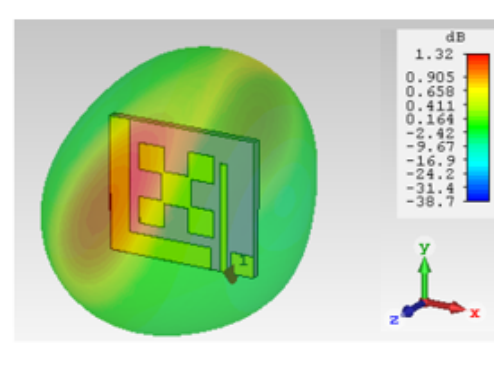

$3.76 \mathrm{GHz}$

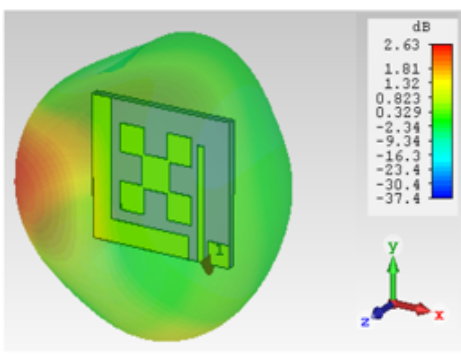

$5 \mathrm{GHz}$

(b)

Figure 7: Antenna performance based on: (a) $S_{11}$ spectra and (b) 3D radiation patterns at different frequency bands

Next, four PIN-diode are added to the proposed antenna structure. Diodes are connected between L-shaped reflector and fractal structure as shown in Fig. 8. These diodes work to give more current manipulation in the antenna structure to change both the operating frequency and radiation patterns. The proposed antenna based on a fractal structure with four diodes is simulated. Four cases are presented here; all diodes are OFF, all diodes are ON, Upper diodes are ON while the lower is OFF, and Upper diodes are OFF while the lower is ON. The antenna results in terms of $S_{11}$ are presented in Fig. 9. In the first case, it is found that the antenna has two frequency bands. The first one has a resonant at $3.76 \mathrm{GHz}$ with an $S_{11}$ value equal to $-30.45 \mathrm{~dB}$, the second one is found from $4.76 \mathrm{GHz}$ to $6.94 \mathrm{GHz}$ with $S_{11}$ equal to $-19.3 \mathrm{~dB}$ as the best value at a frequency of $5 \mathrm{GHz}$. In the second case, the proposed antenna shows two bands. The first band is found at $3.62 \mathrm{GHz}$ with an $S_{11}$ value equal to $-30 \mathrm{~dB}$, while the second band is found starting from $4.59 \mathrm{GHz}$ to $7.6 \mathrm{GHz}$ with a minimum $S_{11}$ value at $5 \mathrm{GHz}$ and $7 \mathrm{GHz}$. In the third case, the antenna shows three resonant frequencies, first one is found at 3.9 $\mathrm{GHz}$ with an $\mathrm{S} 11$ value equal to $-11 \mathrm{~dB}$, the second frequency is found at $4.9 \mathrm{GHz}$ with an $\mathrm{S} 11$ value equal to $-15.46 \mathrm{~dB}$, and the third one is resonant at $6.5 \mathrm{GHz}$ with $\mathrm{S} 11$ value equal to $-15.68 \mathrm{~dB}$. In the last case, the obtained result shows two bands. The first one is at $3.65 \mathrm{GHz}$ with $S_{11}$ equal to $-19.2 \mathrm{~dB}$. The second one is found starting from $4.74 \mathrm{GHz}$ to 
7.6 $\mathrm{GHz}$ with minimum $S_{11}$ value at $5 \mathrm{GHz}$ and $7.1 \mathrm{GHz}$ that equals $-20 \mathrm{~dB}$ and $-22 \mathrm{~dB}$, respectively. Finally, the HFSS is invoked too for more result accuracy validation. So, the difference between CST and HFSS is due to the same reason mentioned previously.

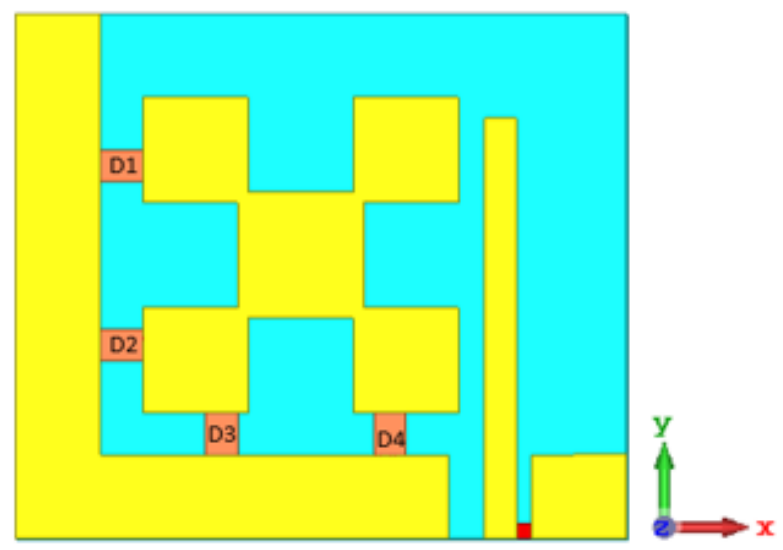

Figure 8: Reconfigurable antenna design based on fractal structure

The radiation patterns of the reconfigurable antenna based on fractal structure are obtained for only four cases: All diodes are OFF, all diodes are ON, Upper diodes are ON while the lower is OFF, and Upper diodes are OFF while the lower is ON. The antenna results are presented in Fig. 10. The antenna radiation is found to change according to the diode switching cases. In the first case, the radiation is found to be a broadside radiator, above and below the antenna, at the first resonant frequency, while it is found to be close to endfire at $5 \mathrm{GHz}$. In the second case, the radiation is found to be very close to the endfire direction in the first and second resonant frequency; however, it is converted to a broadside at $7 \mathrm{GHz}$. In the third case, the antenna is radiating to the left side in the first and second resonant frequencies, while it is radiating to the right side in the last resonant frequency. Finally, in the last case, the radiation patterns are found completely at the endfire direction. In the First resonant, the radiation is endfire to the right antenna side. in the second resonant, the radiation is endfire to the left antenna side. In the last resonant, the radiation is close to Omni-direction, vertical circular shape. Table IV shows the comparison of antenna performance with other published work.

TABLE IV

Antenna Performance with Other Published Results

\begin{tabular}{|c|c|c|c|c|c|c|}
\hline Ref. & $\begin{array}{c}\text { Size/ } \\
\mathrm{mm}^{2}\end{array}$ & (Substrate) & $\begin{array}{c}\text { RF. } \\
\text { switch }\end{array}$ & (B.W)/ GHz & $\begin{array}{c}\text { Diodes, } \\
\text { number }\end{array}$ & $\begin{array}{c}\text { Design } \\
\text {.Complexity }\end{array}$ \\
\hline$[16]$ & $30 \times 60$ & INP & Varactor & 2 & 2 & High \\
\hline$[19]$ & $50 \times 50$ & FR4 & PIN & $(2.5-10)$ & 2 & High \\
\hline $\begin{array}{l}\text { Proposed } \\
\text { work }\end{array}$ & $29 \times 25$ & FR4 & PIN & $\begin{array}{l}(3.8-5.1) \\
\text { and (5.9-7.76) }\end{array}$ & 4 & Low \\
\hline
\end{tabular}


Iraqi Journal of Information and Communications Technology(IJICT)

Conference Series: The $1^{\text {st }}$ Conference of Applied Researches in Information Engineering(ARIE2021), 2021

ISSN:2222-758X e-ISSN:2789-7362

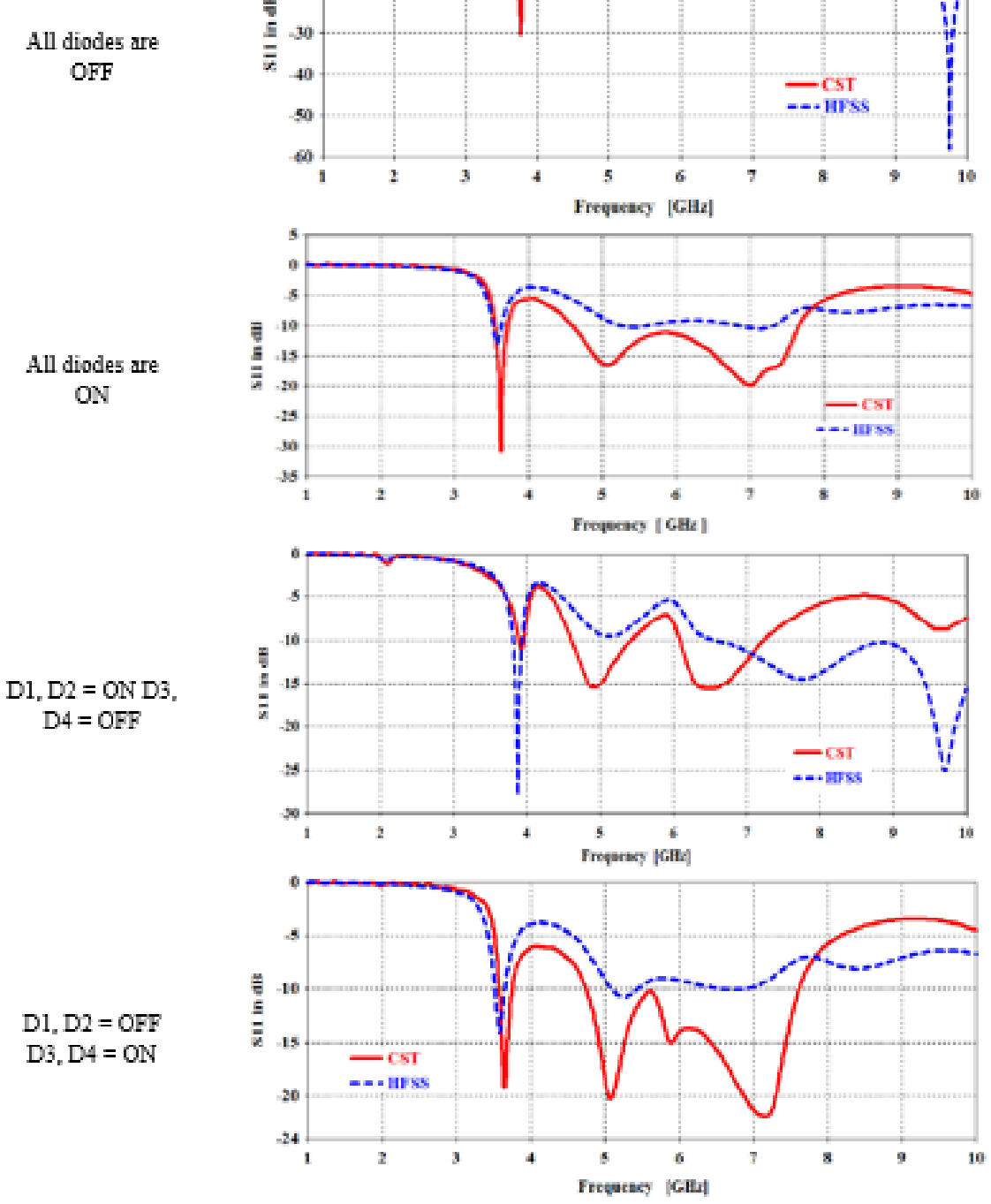

Figure 9: $S_{11}$ results of the reconfigurable antenna based on fractal structure 


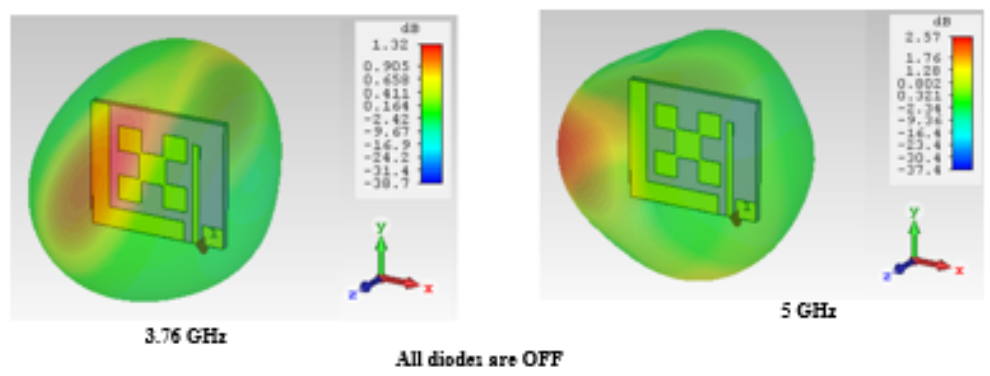

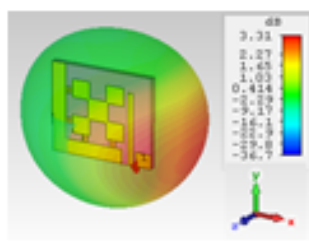

$3.6 \mathrm{GHz}$

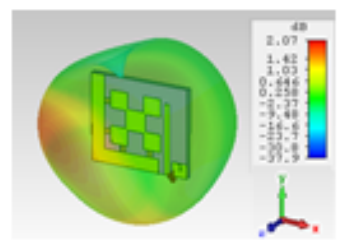

$5 \mathrm{GHz}$

All diodes are ON
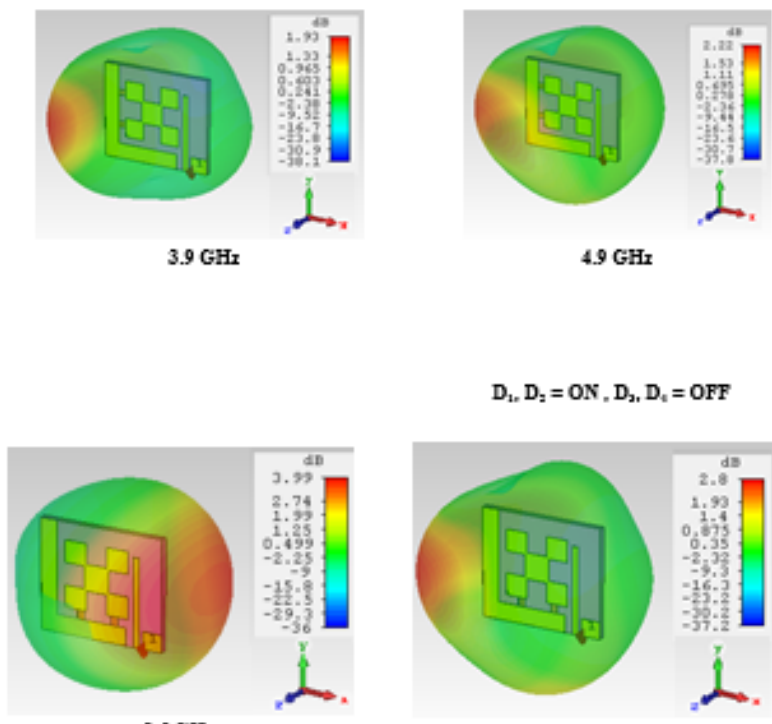

$3.6 \mathrm{GHz}$

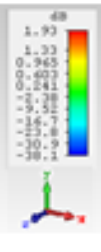

$3.9 \mathrm{GHz}$
$\mathrm{D}_{1} \mathrm{D}_{2}=\mathrm{ON}, \mathrm{D}_{2}, \mathrm{D}_{4}=\mathrm{OFF}$

$4.9 \mathrm{GHz}$

$\mathrm{D}_{1}, \mathrm{D}_{2}=\mathrm{OFF}, \mathrm{D}_{2}, \mathrm{D}_{4}=\mathrm{ON}$

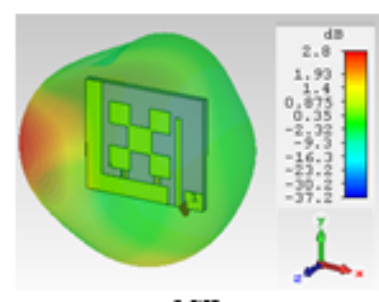

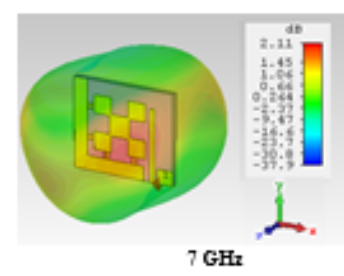
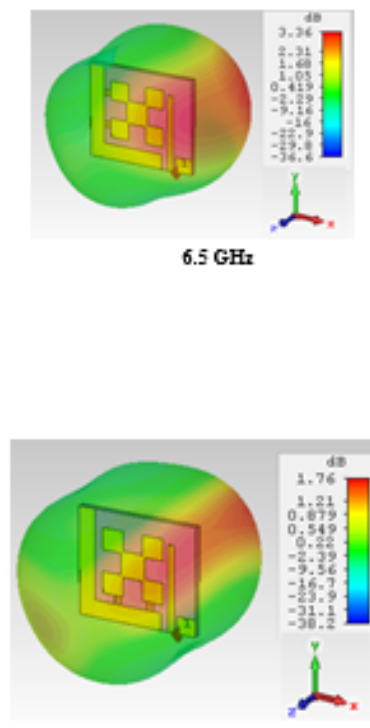

$7.1 \mathrm{GHz}$

Figure 10: 3D radiation patterns of the reconfigurable antenna based on MTM structure

\section{ConClusion}

The monopole antenna based on a fractal structure with four diodes is designed and simulated in this paper. Four cases of PIN diodes switching are presented in this work. Each case showed different operating frequency and radiation patterns. In the first case, two frequency bands are achieved, $3.76 \mathrm{GHz}$ with an $S_{11}$ value equal to $-30.45 \mathrm{~dB}$, and $4.76 \mathrm{GHz}$ to $6.94 \mathrm{GHz}$ with $-19.3 \mathrm{~dB}$ at $5 \mathrm{GHz}$. In the second case, two bands are found at $3.62 \mathrm{GHz}$ with $-30 \mathrm{~dB}$ and $4.59 \mathrm{GHz}$ to 
Iraqi Journal of Information and Communications Technology(IJICT)

Conference Series: The $1^{\text {st }}$ Conference of Applied Researches

in Information Engineering(ARIE2021), 2021

ISSN:2222-758X

e-ISSN:2789-7362

7.6 GHz with minimum $S_{11}$ at $5 \mathrm{GHz}$ and $7 \mathrm{GHz}$. In the third case, the antenna is resonant at $3.9 \mathrm{GHz}, 4.9 \mathrm{GHz}$, and $6.5 \mathrm{GHz}$ with $\mathrm{S} 11$ values equal to $-11 \mathrm{~dB},-15.46 \mathrm{~dB}$, and $-15.68 \mathrm{~dB}$, respectively. In the last case, two bands are found at $3.65 \mathrm{GHz}$ with $S_{11}$ equal to $-19.2 \mathrm{~dB}$ and from $4.74 \mathrm{GHz}$ to $7.6 \mathrm{GHz}$ in terms of the radiation pattern, the results showed different radiation types; broadside, endfire or omnidirectional, according to the selected case. Finally, the HFSS software package is invoked to validate the obtained results.

\section{REFERENCES}

[1] Hammas, H. A, Hasan, M. F, \& Jalal, A. S. A, "Compact Multiband Microstrip Printed Slot Antenna Design for Wireless Communication Applications" , Advanced Electromagnetics, Vol. 9, No. 2, pp. 52-59, 2020.

[2] W. L. Stutzman and G. A. Thiele, "Antenna Theory and Design" , 3rd rev. ed. John Wiley \& Son, 2012.

[3] N. Q. Abdulmohsen AlShaikhli and A. Sadeq Abdulhadi Jalal, "Miniaturized Double-Patch Antenna Design for WLAN Communication with CSRR DGS", Third Scientific Conference of Electrical Engineering (SCEE), Baghdad, Iraq, pp. 226-229, 2018.

[4] G. Jin, L. Li, W. Wang, and S. Liao, "Broadband polarization Reconfigurable Antenna Based on Crossed Dipole and Parasitic Elements for LTE/Sub-6 GHz 5G and WLAN Applications", IET Microwaves, Antennas Propag., Vol. 14, No. 12, pp. 1469-1475, 2020.

[5] A. Panahi, "Reconfigurable Monopole Antennas with Circular Polarization" , No. July, 2015.

[6] A. R. H. Alhawari, A. Ismail, A. S. A. Jalal, R. S. A. Raja Abdullah, and M. F. A. Rasid, "U-Shaped Inductively Coupled Feed RFID Tag Antenna for Gain Enhancement", IEEE Int. Conf. RFID-Technologies Appl. RFID-TA, pp. 4-5, 2013.

[7] A. S. A. Jalal and A. Ismail, "A Compact Fractal-Based Asymmetrical Dipole Antenna for RFID Tag Applications" , Third Scientific Conference of Electrical Engineering (SCEE), Baghdad, Iraq, pp. 101-104, 2018.

[8] T. A. Elwi, "Remotely Controlled Reconfigurable Antenna for Modern 5G Networks Applications" , Microw. Opt. Technol. Lett. , No. December, pp. 1-6, 2020.

[9] Mak, A.C, Rowell, C.R. and Murch, R.D, "Low Cost Reconfigurable Landstorfer Planar Antenna Array" , IEEE transactions on antennas and propagation, Vol. 57, No. 10, pp. pp. 3051-3061,2009.

[10] Abdulhameed, A. A., Alhamdawee, E. M, \& Hayder, I. M, "Review of Reconfigurable/UWB Antenna for Interweave Cognitive Radio Applications" , Australian Journal of Electrical and Electronics Engineering, Vol. 16, No. 2, pp. 96-101, 2019.

[11] Sadek, S, Essaaidi, M, Gong, L, Ramer, R, \& Yuk, K, "Beam Steering Spiral Antenna Reconfigured by PIN Diodes" , International Journal of Microwave and Wireless Technologies, Vol. 6, No. 6, p. 619, 2014.

[12] Rashidian, A, Aligodarz, M. T, Klymyshyn, D. M, Boerner, M, Shafai, L, \& Mohr, J, "Fabrication of Photoresist-Based Polymer Resonator Antennas Using Ultra-Thick SU-8 Based Dry Films", In 2013 IEEE Antennas and Propagation Society International Symposium (APSURSI), pp. 1298-1299, IEEE, July, 2013.

[13] Li, R, Yang, H, Liu, B, Qin, Y, \& Cui, Y, "Theory and Realization of a Pattern-Reconfigurable Antenna Based on Two Dipoles" , IEEE Antennas and Wireless Propagation Letters, Vol. 17, No. 7, pp. 1291-1295, 2018.

[14] Liu, F, Zhang, Z, Chen, W, Feng, Z, \& Iskander, M. F, " An Endfire Beam-Switchable Antenna Array Used in Vehicular Environment" , IEEE Antennas and Wireless Propagation Letters, No. 9,pp. 195-198, 2010.

[15] Y. Al Naiemy, T. A. Elwi, and L. Nagy, "An End Fire Printed Monopole Antenna Based on Electromagnetic Band Gap Structure" , Automatika, Vol. 61, No. 3, pp. 482-495, 2020.

[16] T. A. Elwi and B. A. Ahmad, "A Fractal Metamaterial Based Printed Dipoles on a Nickel Oxide Polymer Palm Fiber Substrate for Wi-Fi Applications" , AEU-Int. J. Electron. Commun., Vol. 96, pp. 122-129, 2018.

[17] Alhalboosi, H.A, Kurnaz, S. and Shantaf, A.M, "Design of Double H-Slot Microstrip Patch Triple-Band for C-Band" , In International Congress on Human-Computer Interaction, Optimization and Robotic Applications (HORA), pp. 1-4, IEEE, June, 2020.

[18] A.S. A Jalal,"A New Compact Patch Antenna Design for Circular Polarization Application Based on 3rd Iteration Minkowski Like Pre Fractal Geometry", Journal of Engineering and Applied Sciences, Vol. 3, No. 9, pp. 729-734.

[19] B. Belkadi, Z. Mahdjoub, M. L. Seddiki and M. Nedil, "UWB Monopole Antenna with Reconfigurable Notch Bands based on Metamaterials Resonators" ,IEEE International Symposium on Antennas and Propagation \& USNC/URSI National Radio Science Meeting, pp. 285-286, 2018. 